\title{
4-Methylumbelliferone leads to growth arrest and apoptosis in canine mammary tumor cells
}

\author{
TERUYOSHI SAITO, DAI TAMURA, TATSURO NAKAMURA, YUKIHISA MAKITA, \\ HITOMI ARIYAMA, KEIJI KOMIYAMA, TOMOKO YOSHIHARA and RYUJI ASANO \\ Laboratory of Veterinary Pharmacology, Nihon University College of Bioresource Sciences, \\ 1866 Kameino, Fujisawa, Kanagawa 252-8510, Japan
}

Received August 21, 2012; Accepted September 26, 2012

DOI: $10.3892 /$ or.2012.2100

\begin{abstract}
Hyaluronan (HA), a major component of the extracellular matrix (ECM), is synthesized by HA synthase (HAS) 1, HAS2 and HAS3 and is intricately involved in cell growth and metastasis. The HA synthesis inhibitor 4-methylumbelliferone (4-MU) has been reported to exhibit anticancer properties in various types of malignant tumors. However, the underlying mechanisms at the molecular and cellular levels remain unclear. In this study, to establish an animal model for studying the function of HA in human breast cancer, we investigated the antitumor effects of 4-MU using canine mammary tumor (CF33) cells. First, we investigated the effects of 4-MU on HA production in $\mathrm{CF} 33$ cells. Quantitative analysis of HA in culture media showed that 4-MU inhibited HA synthesis, accompanied by downregulation of HAS 2 mRNA levels, in a dose-dependent manner at 24-72 h. Additionally, we observed a 4-MU-mediated decrease in the extent of the cell-associated HA matrix. We examined the effect of 4-MU on cell growth and apoptosis in CF33 cells. 4-MU markedly inhibited cell proliferation and induced apoptosis in CF33 cells. In particular, our experiments showed that the mechanism of 4-MU-induced apoptosis in CF33 cells involved increased levels of expression of pro-apoptotic BAX mRNA and protein molecules. These data suggest that 4-MU may be a candidate therapeutic agent for the treatment of canine mammary tumors. Furthermore, this study provides the first indication that the canine mammary tumor may be a suitable model for comparative study of the function of HA in human breast cancer.
\end{abstract}

\section{Introduction}

Mammary tumors in dogs occur at a frequency of 3 times the incidence of mammary tumors in humans and have recorded

Correspondence to: Dr Teruyoshi Saito, Laboratory of Veterinary Pharmacology, Nihon University College of Bioresource Sciences, 1866 Kameino, Fujisawa, Kanagawa 252-0880, Japan

E-mail: saitou.teruyoshi@nihon-u.ac.jp

Key words: 4-methylumbelliferone, hyaluronan, hyaluronan synthase, apoptosis, canine mammary tumor a higher incidence rate than other livestock (1). Mammary tumors are the most frequent cutaneous neoplasms in female dogs, and approximately $50 \%$ are diagnosed as malignant tumors (2). Following surgical excision, approximately $48 \%$ of the affected dogs die or are euthanized within 1 year due to tumor recurrence or metastasis (3). Canine mammary tumors are heterogeneous, and the different clinical and biological features (4) make it difficult to determine a prognosis and treatment for affected dogs, as is often the case in humans. Additional and reliable tools for effective therapy are required in veterinary medicine. Furthermore, a recent study revealed clear evidence of a similarity between human and dog tumors in regard to the deregulation of several cancer-related genes, including PI3K/Akt, PTEN and Wnt- $\beta$ catenin and MAPK signaling (5). Accordingly, canine mammary tumors can also provide a suitable natural model for the comparative study of human breast cancer (5-7).

Hyaluronan (HA) is a non-sulfated linear glycosaminoglycan that consists of repeating disaccharide subunits of glucuronic acid and $\mathrm{N}$-acetylglucosamine $(8,9)$. It is ubiquitously distributed in the extra- and pericellular spaces of most animal tissues $(8,9)$. HA plays a critical role in regulating matrix assembly, cell migration, differentiation and proliferation (9-11). Thus, production of HA increases during active tissue remodeling, e.g., during embryonic development and wound healing (12). In cancer, previous studies have shown that high stromal HA levels correlate with tumor aggressiveness and low survival rates in patients with breast, ovarian and prostate cancer (13-15). Similarly, in vitro studies have demonstrated that the inhibition of HA synthesis correlates with the downregulation of proliferative, invasive and metastatic potential in cancer cells (16-18).

In vertebrates, $\mathrm{HA}$ is synthesized at the plasma membrane by 3 HA synthases, HAS1, 2 and 3, which couple glucuronic acid (GlcUA) and $\mathrm{N}$-acetylglucosamine (GlcNAc) into a linear polymer using the corresponding UDP-sugars (UDP-GlcUA and UDP-GlcNAc) as substrates. HA is secreted as a free glycosaminoglycan and tethered at the cell surface via several HA receptors including as CD44 and RHAMM (receptor for HA-mediated motility) (19,20). Increasing levels of pericellular HA may help maintain the malignant phenotype of cancer cells by providing a suitable environment (21). Interaction of HA with HA receptors stimulates signaling events such as 
anchorage-independent tumor cell growth, survival and migration, thereby increasing metastatic spread (22). Furthermore, CD44 is overexpressed in several human types of cancer and previous reports have shown that an HA-CD44 interaction causes activation of EGFR (epidermal growth factor receptor)-, PI3 kinase-, MAP kinase- and Rho-mediated signaling pathways that promote tumor growth, migration and chemotherapeutic resistance. Expression of CD44 has also been confirmed in canine mammary and melanocytic tumor tissues by immunohistochemistry $(23,24)$. Therefore, as in humans, the inhibition of the HA-CD44 interaction might be regarded as a novel therapeutic target in mammary tumors in dogs.

4-Methylumbelliferone (4-MU: 7-hydroxy-4-methyl-2H1-benzopyran-2-one) was previously reported to specifically inhibit synthesis of HA in cultured human skin fibroblasts (25). Studies of the mechanism of action revealed that 4-MU induced inhibition of HA synthesis involving the glucuronidation of 4-MU by endogenous UDP-glucuronyltransferases (UGT) resulting in a depletion of UDP-GlcUA (26). Moreover, it is also known that 4-MU can act by reducing levels of $H A S$ mRNA in breast, melanoma and ovarian cancer cells (27). Some studies have shown anticancer effects of 4-MU through decreased HA synthesis in vitro and in vivo $(28,29)$. However, to our knowledge, no study examining the anticancer effect of 4-MU on canine mammary tumors has been published.

In this study, we hypothesized that inhibition of HA production by 4-MU would negatively regulate the tumor growth of canine mammary tumors. To assess our hypothesis, we analyzed the effects of 4-MU on cell growth and apoptosis in CF33 canine mammary tumor cells. Moreover, in this study, we also assessed whether or not dogs are suitable research models for functional analysis of HA in human breast cancer.

\section{Materials and methods}

Materials. 4-Methylumbelliferone (4-MU) was purchased from Wako Pure Chemicals (Osaka, Japan). An anti-BAX antibody (ABC11) was obtained from Millipore (Bedford, MA, USA). An anti- $\beta$-actin antibody (AC-15) was purchased from Sigma (St. Louis, MO, USA). 3-(4,5-Dimethyl-2-thiazolyl)2,5-diphenyl-2H-tetrazolium bromide for the MTT assay and hyaluronidase were purchased from Sigma.

Cell culture. Cells from the canine breast cancer cell line CF33 were obtained from the American Type Culture Collection (Manassas, VA, USA). The cells were grown as monolayers, cultured in DMEM (Nissui, Tokyo, Japan) supplemented with $10 \%$ heat-inactivated fetal bovine serum (FBS), $4 \mathrm{mM}$ L-glutamine, $10 \mathrm{mg} / \mathrm{ml}$ streptomycin and $10,000=\mathrm{U} / \mathrm{ml}$ penicillin $\mathrm{G}$. The cells were maintained at $37^{\circ} \mathrm{C}$ in a $5 \% \mathrm{CO}_{2}$ incubator. The 4-MU stock solution for experiments was dissolved in DMSO and the final concentration of DMSO in the medium was adjusted to $0.1 \%$.

Quantification of HA. To determine the effect of 4-MU on CF33 cells, we quantified HA in conditioned medium using a commercially available competitive enzyme-linked immunosorbent assay kit (ELISA) (Echelon Biosciences, Salt Lake City, UT, USA), in which the colorimetric signal was inversely proportional to the amount of HA present in the sample.
Particle exclusion assays. To analyze the effect of 4-MU on the areas of the HA-rich pericellular matrices, we used a particle exclusion assay. Fixed sheep erythrocytes (Sigma) were reconstituted in phosphate-buffered saline (PBS) to a density of $5.4 \times 10^{8}$ cells $/ \mathrm{ml}$ and used for the particle exclusion assay as previously described (30). HA matrices were visualized by adding $6.0 \times 10^{7}$ erythrocytes to the growth medium and viewing under an All-in-One Fluorescence Microscope BZ-9000 (Keyence Corp., Osaka, Japan). The HA-rich pericellular matrix-to-cell-area ratios were determined by image analysis using ImageJ. All measurements were made by tracing the digitized images. Non-treated medium and hyaluronidasecontaining medium served as negative and positive controls, respectively.

MTT assay. The MTT assay, which is widely used to measure cell proliferation and to screen for anticancer drugs, is based on the reduction of a tetrazolium salt (31-33). We used the MTT assay to evaluate the effects of the 4-MU on cell proliferation. CF33 cells were plated in 96-well plates at $1 \times 10^{3}$ cells/well. At each time point (days 0-4), $20 \mu \mathrm{l}$ of MTT reagent was added and the plates were incubated for $4 \mathrm{~h}$. Subsequently, $100 \mu \mathrm{l}$ of $10 \%$ SDS and $0.01 \mathrm{~N} \mathrm{HCl}$ were added to each well. Following overnight incubation, the absorbances were measured at $570 \mathrm{~nm}$ using a Model 550 microplate reader (Bio-Rad Laboratories, Tokyo, Japan). In these experiments, 5 replicate wells were used for each time point and the results were calculated as the means $\pm \mathrm{SD}$.

Cell cycle and apoptosis analysis. Cells were harvested and washed with PBS, resuspended in $70 \%$ ethanol in distilled water and kept at $-30^{\circ} \mathrm{C}$ overnight. Prior to analysis, cells were mixed and incubated for $30 \mathrm{~min}$ in PBS containing $0.05 \mathrm{mg} / \mathrm{ml}$ propidium iodide (PI) and $100 \mathrm{U} / \mathrm{ml}$ RNase A. The suspension was then passed through a nylon mesh filter and analyzed by FACSCalibur (Becton-Dickinson, Franklin Lakes, NJ, USA). Furthermore, these data were analyzed using FlowJo 7 (Tree Star, Inc., Ashland, OR, USA).

Real-time RT-PCR. Total-RNA was extracted from cells using the TRIzol reagent (Invitrogen, Carlsbad, CA, USA) and cDNAs were synthesized with a PrimeScript ${ }^{\mathrm{TM}}$ RT reagent kit (Takara Bio, Inc., Shiga, Japan) according to the manufacturer's protocols. Real-time PCR was performed using SYBR Premix Ex Taq ${ }^{\mathrm{TM}}$ (Takara Bio) and an ABI Prism 7500 Real-Time PCR system (Applied Biosystems, Foster City, CA, USA) under the following conditions: $30 \mathrm{sec}$ at $95^{\circ} \mathrm{C} ; 40$ cycles of $5 \mathrm{sec}$ at $95^{\circ} \mathrm{C}$ and $34 \mathrm{sec}$ at $60^{\circ} \mathrm{C}$. Specific primer sets for $B A X$ (forward, 5'-CGCATCGGAGATGAACTGGA-3'; and reverse, 5'-ACCAGTTTGCTGGCAAAGTAGAAG-3') were purchased from Takara Bio, Inc. HAS1 (forward, 5'-GGACTACG TGCAGGTGTGTG-3'; reverse, 5'-CTCACCTAGGGGAC CACTGA-3'), HAS2 (forward, 5'-CTTAGAGCACTGGGA-3'; reverse, 5'-TCTAAAACTTTCACCA-3'), HAS3 (forward, 5'-AAGTAGGGGGAGTTGG-3'; reverse, 5'-CCCAGAGGC CCACTAA-3'), and GAPDH (forward, 5'-AAGGCTGAGA ACGGGA-3'; reverse, 5'-GGAGGCATTGCTGACA-3') were obtained from Operon Biotechnologies (Tokyo, Japan). The specificity of each amplification was confirmed by a dissociation curve consisting of a single peak. All samples were 


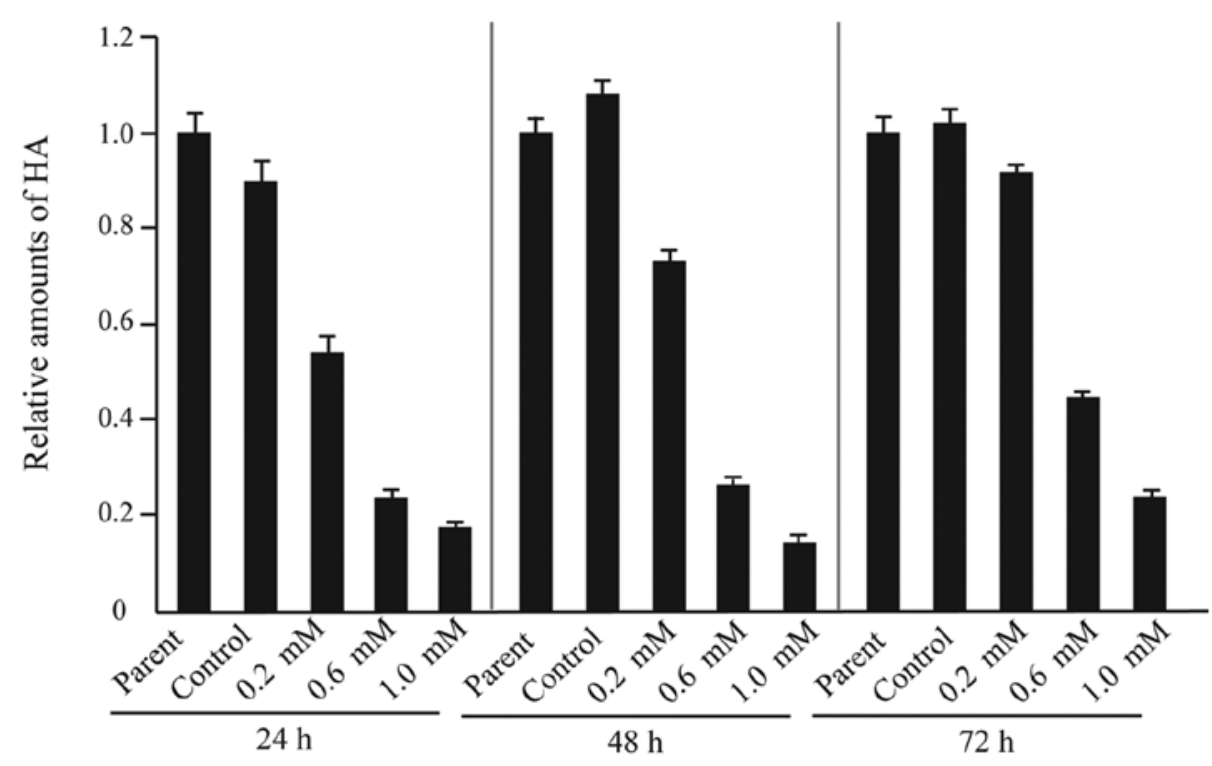

Figure 1. 4-MU decreases HA synthesis. HA contents in the conditioned medium were measured by ELISA-like assay at 24,48 and $72 \mathrm{~h}$ after the treatment with 0.2, 0.6 and $1.0 \mathrm{mM}$ 4-MU. As a control, CF33 cells were added with DMSO at a final concentration of $0.1 \%$. The data represent the means \pm SD, each analysis was performed in triplicate.

amplified in triplicate in each experiment. The values were normalized by the expression of GAPDH.

Western blotting. Whole cell lysates were prepared with icecold RIPA buffer (50 mM Tris- $\mathrm{HCl}$ pH 7.5, $1 \%$ nonidet $\mathrm{P}-40$, $150 \mathrm{mM} \mathrm{NaCl}, 0.1 \%$ SDS, $0.5 \%$ deoxycholic acid) containing $1 \mu \mathrm{g} / \mathrm{ml}$ leupeptin, $1 \mu \mathrm{g} / \mathrm{ml}$ pepstatin, $1 \mu \mathrm{g} / \mathrm{ml}$ aprotinin, $1 \mathrm{mM}$ DTT, $1 \mathrm{mM} \mathrm{NaVO}$ and $0.5 \mathrm{mM}$ PMSF. The supernatants were saved as total cell lysates following centrifugation. Aliquots of the cell lysates (20 $\mu \mathrm{g}$ of protein) were separated by $12 \%$ SDS-PAGE and transferred to PVDF membranes (ATTO, Tokyo, Japan). Primary antibodies that bound to their antigens on the membranes were detected using appropriate HRP-conjugated secondary antibodies (Amersham Biosciences, Piscataway, NJ, USA) and SuperSignal Chemiluminescence or a WesternBright Sirius western blotting kit (Advansta, Menlo Park, CA, USA) according to the manufacturer's instructions.

Statistical analysis. Statistical comparisons between two groups were made using an unpaired Student's t-test. Values of $\mathrm{P}<0.05$ were considered to indicate a statistically significant difference.

\section{Results}

Inhibitory effect of 4-MU on HA in medium and cell-associated matrix of CF33 cells. 4-MU was originally found to inhibit HA synthesis in cultured human skin fibroblasts (25). To determine the effect of 4-MU on HA synthesis in the CF33 cells, we quantified the levels of HA in conditioned medium using the ELISA assay. As shown in Fig. 1, 4-MU was associated with decreased levels of HA production in a dose-dependent manner at all time points, whereas there was no change in the HA levels between parent cells and vehicle (DMSO)-treated controls. It was previously reported that the cell-associated
HA matrix plays a critical role in the progression of several malignancies $(13,34)$. We confirmed the influence of 4-MU on HA-matrix formation by particle exclusion assay. Abundant accumulation of the cell-associated HA matrix was shown in CF33 cells following incubation with control medium with or without DMSO (Fig. 2A and C). The HA matrix disappeared after treatment with Streptomyces hyaluronidase, indicating that these matrices were comprised of retained HA (Fig. 2B). Cells treated with 4-MU showed a significant dose-dependent decrease in the area of the cell-associated HA matrix and ratio of matrix area to cell area at each time point (Fig. 2D-G). Furthermore, 4-MU treatment caused a change in cell morphology. As seen in Fig. 2C-F, within $72 \mathrm{~h}$ of 4-MU treatment, CF33 cells tended to become flat in form and there was an expansion of the cell area compared with control. These findings suggested that 4-MU inhibited HA synthesis and weakened the cell-associated HA matrix. The observations that 4-MU effectively reduced HA production in canine mammary tumor cells were comparable to those previously reported in human and mouse cells.

HAS2 mRNA levels are downregulated in CF33 cells treated with 4-MU, while HAS3 mRNA levels are upregulated. Three HAS isoforms (HAS1, HAS2, and HAS3) have been identified in mammalian cells. It has been reported that inhibition of HA synthesis by treatment with 4-MU reduced mRNA expression by $H A S 2, H A S 3$, or both, in various cell lines, including melanoma, breast and ovarian cancers (27). To assess the effect of 4-MU on the expression of the HAS genes in CF33 cells, we investigated the expression of $H A S$ using real-time RT-PCR. We found that the expression of HASI mRNA was undetectable in the CF33 cells (data not shown), which mainly expressed HAS2 and HAS3 mRNA. CF33 cells treated with 4-MU showed a tendency to decrease levels of HAS2 mRNA, while the expression of HAS3 was increased (Fig. 3A and B). These data indicated that 4-MU-related inhibition of HA 

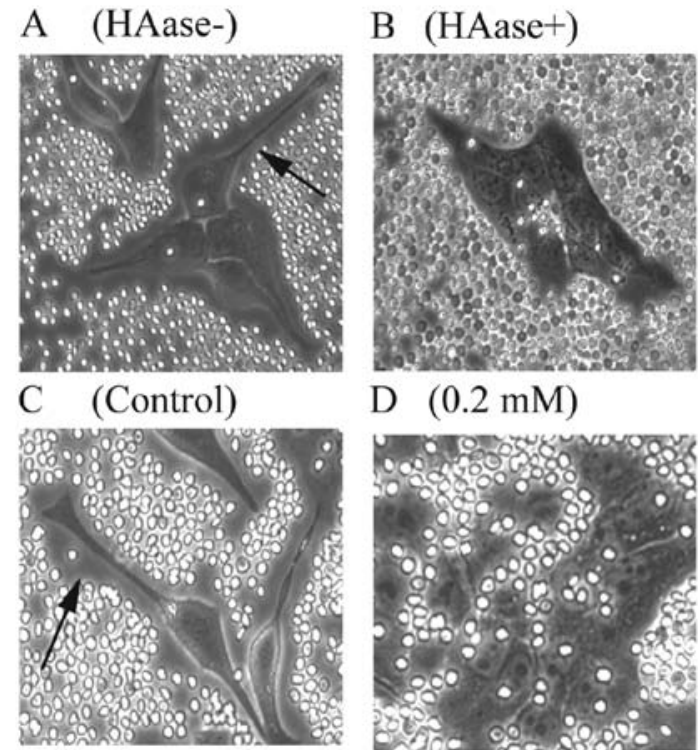

D $(0.2 \mathrm{mM})$
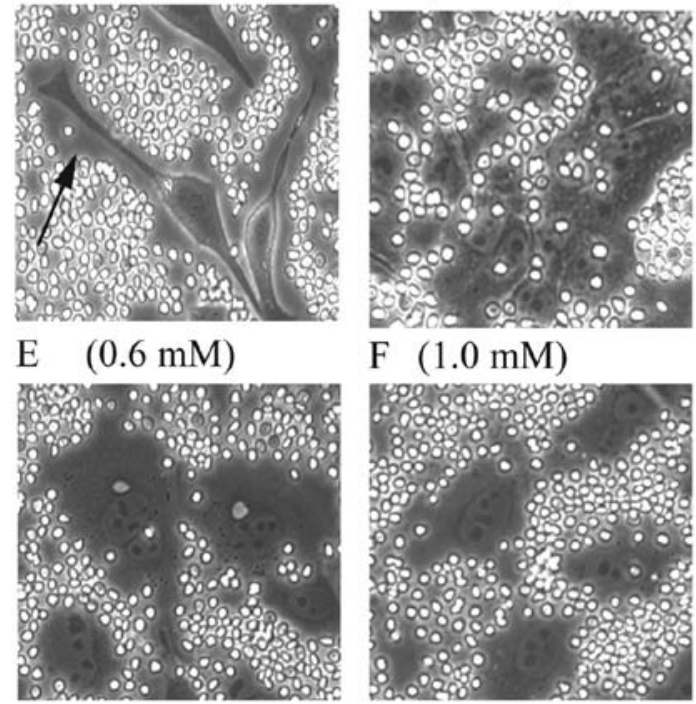

\section{$\mathrm{F}(1.0 \mathrm{mM})$}

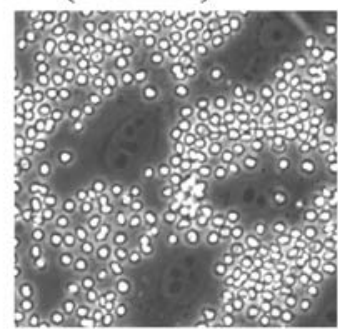

G

\begin{tabular}{|c|c|c|c|}
\hline & $\begin{array}{c}\text { HA-rich } \\
\text { pericellular matrices }\left(\mu \mathrm{m}^{2}\right)\end{array}$ & Matrices:cell area ratio \\
\hline \multirow{4}{*}{$24 \mathrm{~h}$} & $\begin{array}{l}\text { Control } \\
(\mathrm{n}=179)\end{array}$ & $1004.60 \pm 46.72$ & $1.16 \pm 0.087$ \\
\hline & $\begin{array}{l}0.2 \mathrm{mM} \\
(\mathrm{n}=130)\end{array}$ & $491.23 \pm 21.46$ & $0.55 \pm 0.048^{*}$ \\
\hline & $\begin{array}{l}0.6 \mathrm{mM} \\
(\mathrm{n}=114)\end{array}$ & $418.89 \pm 19.64$ & $0.47 \pm 0.044^{*}$ \\
\hline & $\begin{array}{l}1.0 \mathrm{mM} \\
(\mathrm{n}=133)\end{array}$ & $50.12 \pm 10.73$ & $0.19 \pm 0.0162^{*}$ \\
\hline \multirow{4}{*}{$48 \mathrm{~h}$} & $\begin{array}{l}\text { Control } \\
(\mathrm{n}=210)\end{array}$ & $473.70 \pm 18.85$ & $1.07 \pm 0.074$ \\
\hline & $\begin{array}{l}0.2 \mathrm{mM} \\
(\mathrm{n}=155)\end{array}$ & $340.37 \pm 19.25$ & $0.50 \pm 0.040^{*}$ \\
\hline & $\begin{array}{l}0.6 \mathrm{mM} \\
(\mathrm{n}=221)\end{array}$ & $96.07 \pm 12.37$ & $0.025 \pm 0.0015^{*}$ \\
\hline & $\begin{array}{l}1.0 \mathrm{mM} \\
(\mathrm{n}=238)\end{array}$ & $46.96 \pm 7.77$ & $0.029 \pm 0.0019^{*}$ \\
\hline \multirow{4}{*}{$72 \mathrm{~h}$} & $\begin{array}{l}\text { Control } \\
(\mathrm{n}=186)\end{array}$ & $722.47 \pm 30.04$ & $1.57 \pm 0.12$ \\
\hline & $\begin{array}{l}0.2 \mathrm{mM} \\
(\mathrm{n}=120)\end{array}$ & $147.28 \pm 12.29$ & $0.18 \pm 0.016^{*}$ \\
\hline & $\begin{array}{l}0.6 \mathrm{mM} \\
(\mathrm{n}=115)\end{array}$ & $28.61 \pm 3.64$ & $0.061 \pm 0.0057^{*}$ \\
\hline & $\begin{array}{l}1.0 \mathrm{mM} \\
(\mathrm{n}=173)\end{array}$ & $25.80 \pm 8.37$ & $0.017 \pm 0.0013^{*}$ \\
\hline
\end{tabular}

Figure 2. 4-MU reduces HA-rich pericellular matrices in CF33 cells. The HA-rich pericellular matrices were visualized by particle exclusion assay as described in Materials and methods. HA-rich pericellular matrices are shown by arrows. Red blood cell diameter, 7 mm. Original magnification, x200. (A and B) As a control, CF33 cells were treated with or without $10 \mathrm{U} / \mathrm{ml}$ of Streptomyces hyaluronidase before the particle exclusion assay. Representative images of a particle exclusion assay for CF33 cells either untreated or treated with Streptomyces hyaluronidase. (C) CF33 cells were incubated in the presence of vehicle (DMSO) as a negative control. (D-F) CF33 cells were treated with 4-MU at concentrations of 0.2, 0.6 and $1 \mathrm{mM}$, respectively. Representative images of the particle exclusion assay for CF33 cells treated with vehicle or 4-MU are shown. (G) Areas of HA-rich pericellular matrices and matrix-to-cell-area ratios depicted by morphometric analysis. The data shown are the means $\pm \mathrm{SE}$. ${ }^{*} \mathrm{P}<0.01$, vs. control by Student's t-test.
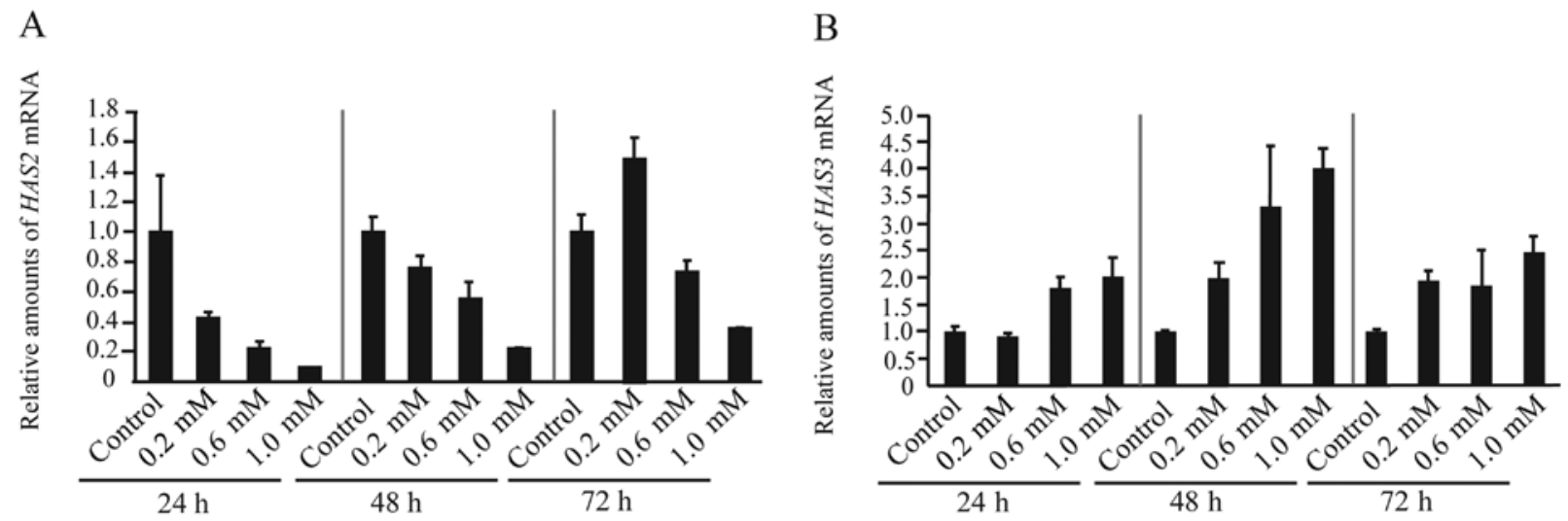

Figure 3. 4-MU induces alteration in expression pattern of HAS2 and HAS3 mRNA. The mRNA levels of HAS1, HAS2 and HAS3 were analyzed by real-time RT-PCR in CF33 cells treated with 4-MU at a concentration of $0.2,0.6$ and $1.0 \mathrm{mM}$, respectively. The data represent the means \pm SD. This analysis was performed in triplicate. (A) Real-time RT-PCR analysis of HAS2 mRNA expression in CF33 cells treated with the vehicle (control) or different concentrations of 4-MU $(0.2,0.6$ and $1.0 \mathrm{mM})$ at 24-72 h. (B) Real-time RT-PCR analysis of HAS3 mRNA expression in CF33 cells treated with the vehicle (control) or different concentrations of 4-MU $(0.2,0.6$ and $1.0 \mathrm{mM})$ at $24-72 \mathrm{~h}$.

synthesis was mainly associated with downregulation of HAS2. The increase in the levels of HAS3 mRNA may signify a back-up system for HA production and these events are likely to occur in HA-related genes $(17,35)$.
4-MU markedly inhibits proliferation of CF33 cells. The rate of cell proliferation is often associated with that of HA synthesis (35). Furthermore, it was previously reported that cell proliferationis inhibited by 4-MU in various cancercells $(27,28)$. 


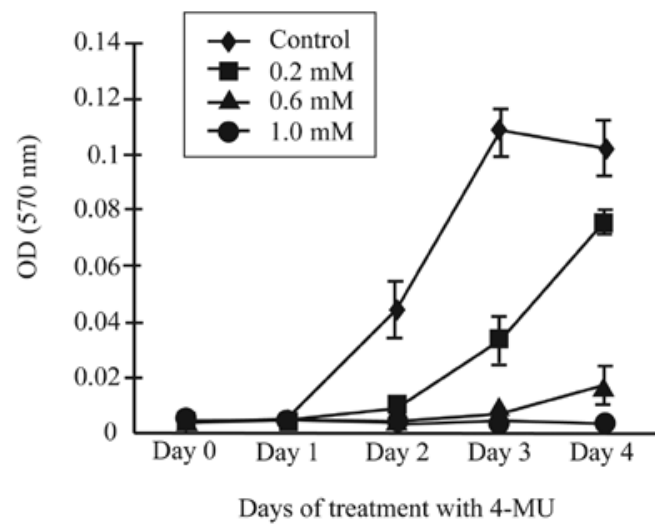

Figure 4. 4-MU markedly inhibits cell proliferation of CF33 cells in a dosedependent manner. The effects of 4-MU on cell proliferation were analyzed by MTT assays from days 0 to 4 of culture. The data shown are the means \pm SD $(n=5)$. Closed rhombuses represent cells treated with vehicle. Cells treated with a different concentration of 4-MU $(0.2,0.6$ and $1.0 \mathrm{mM})$ are indicated by closed squares, closed triangles and closed circles, respectively.

Cell proliferation was assayed in the CF33 cells by MTT assay upon addition of 4-MU and at 0,1,2,3 and 4 days later (Fig. 4). The number of cells in control cultures increased steadily during the days following plating, while the proliferation rate was dose-dependently suppressed by $0.2,0.6$ and $1.0 \mathrm{mM}$ concentrations of 4-MU (Fig. 4). Notably, by day 4 of the $1.0 \mathrm{mM} 4-\mathrm{MU}$ treatment, proliferation was completely blocked (Fig. 4). This result demonstrated that 4-MU was able to inhibit the growth of canine mammary tumor cells as it has in the several other cancer cell types mentioned.

4-MU induces G2/M phase cell cycle arrest and subsequent apoptosis. 4-MU caused marked inhibition of the proliferation of CF33 cells in our experiments, and to determine whether 4-MU is associated with alteration of cell cycle progression in the CF33 cells, cells were grown to $70 \%$ confluence and the cell cycle distribution was analyzed by flow cytometry after 24-, 48- and 72-h exposure to 4-MU (0.2, 0.6 and $1.0 \mathrm{mM})$. Among the cells treated with $1.0 \mathrm{mM} 4-\mathrm{MU}$ at each time point, the percentage of cells in the $\mathrm{S}$ phase was lower than the corresponding value for the control cells, and the percentage of cells in the G2/M phases in cultures treated with $1.0 \mathrm{mM} 4-\mathrm{MU}$ was significantly higher than in the corresponding control cells (Fig. 5A-C). Following G2/M arrest, several cancer cell lines, notably certain breast cancer cell lines, exhibit morphologic changes consistent with apoptosis, i.e., plasma membrane blebbing, the appearance of a rounded morphology and eventual detachment from the surface of the tissue culture dish where the epithelial cancer cell lines normally grow as an adherent monolayer (36). The percentage of apoptotic cells in our specimens was quantified with PI staining and flow cytometric analysis, with the sub-G0/G1 peak representing apoptotic cells. As shown in Fig. 5D, apoptosis was induced more frequently
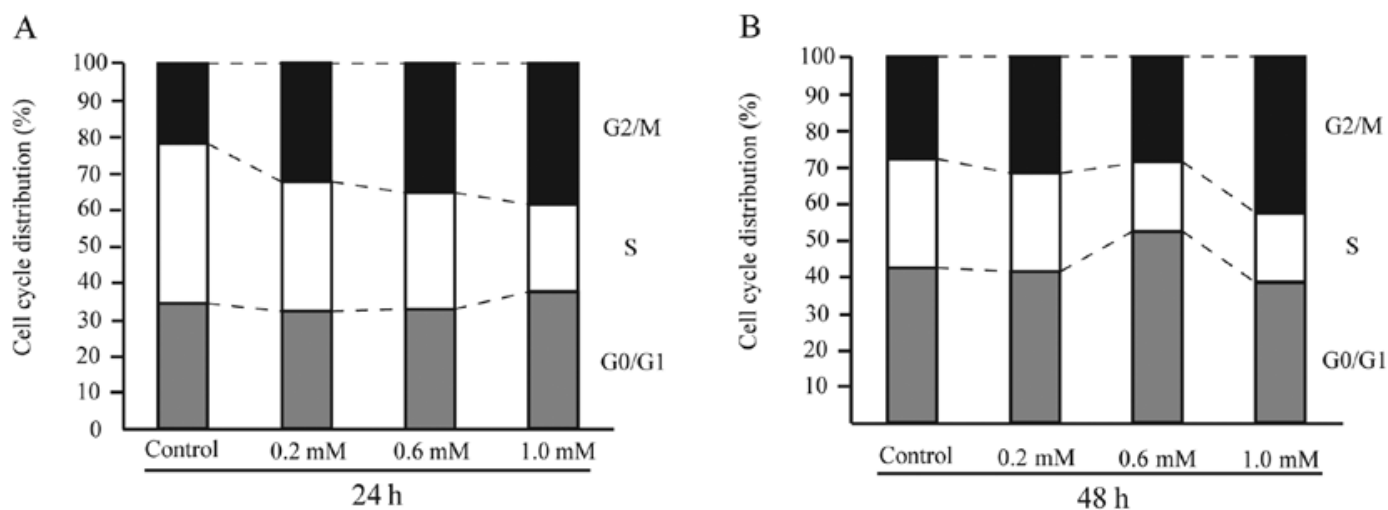

C

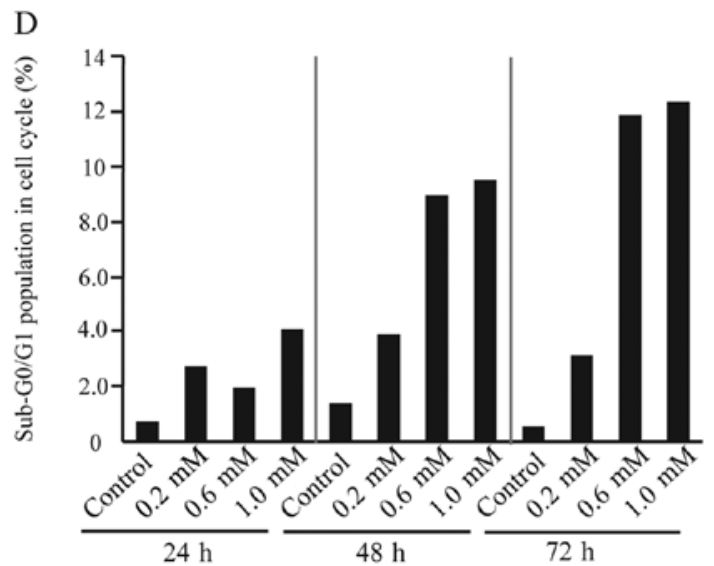

Figure 5. 4-MU leads to a reduction in S-phase cells and an increase in apoptotic cells. The effects of 4-MU on the distribution of cell cycle were estimated by flow cytometric analysis. (A-C). These results showed the percentage of cells distributed in each cell-cycle stage. Cells were treated with vehicle (control) or 4-MU $(0.2,0.6$ or $1.0 \mathrm{mM})$ for the indicated time periods. (D) Flow cytometric analysis of apoptotic cells treated with the vehicle (control) or different concentrations of 4-MU $(0.2,0.6$ and $1.0 \mathrm{mM})$ at $24-72 \mathrm{~h}$. These data were obtained by analyzing 20,000 cells in each experiment. 
A

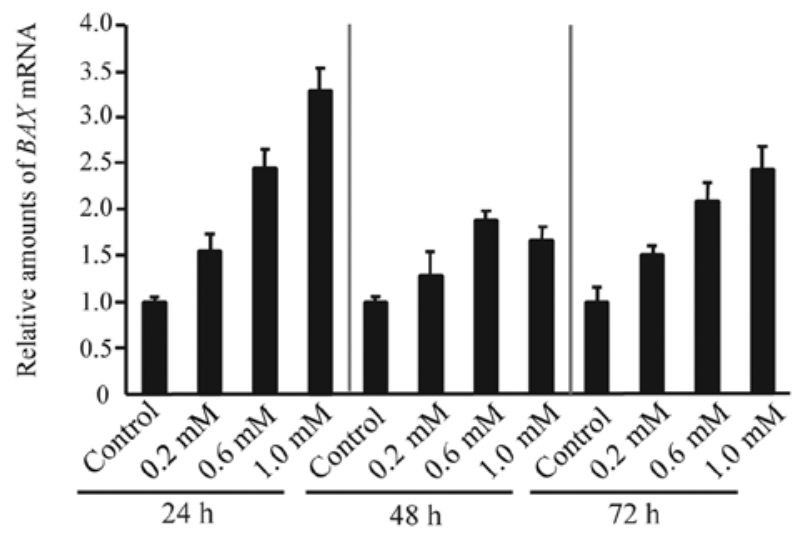

B

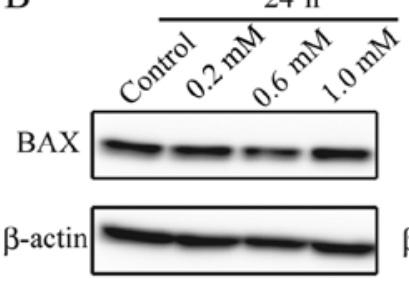

$\mathrm{C}$
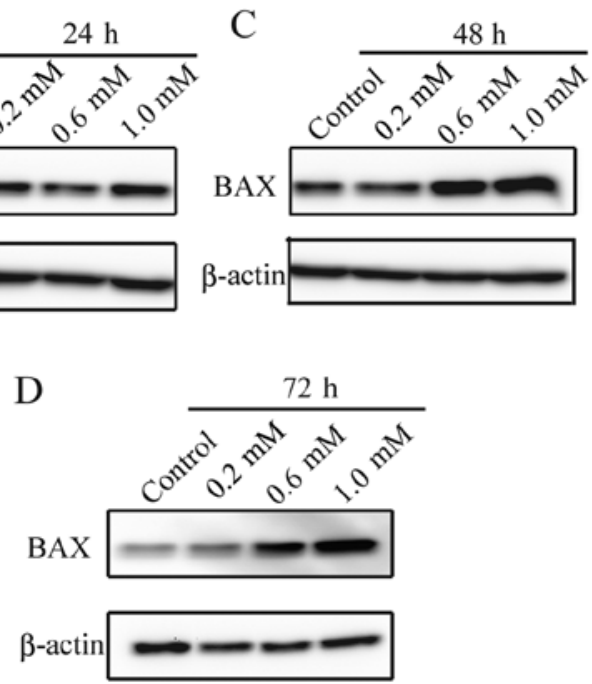

Figure 6. 4-MU induces apoptosis accompanied by elevation of $B A X$ expression. To observe the effect of 4-MU on apoptosis-related proteins, we measured $B A X$ mRNA and protein expression using real-time RT-PCR and western blotting. (A) $B A X$ mRNA expression in CF33 cells treated with 4-MU was measured using real-time RT-PCR analyses at 24-72 $\mathrm{h}$. The data represent the means \pm SD. This analysis was performed in triplicate. (B-D) Western blotting for BAX in CF33 cells treated with vehicle (control) or 4-MU $(0.2,0.6$, or $1.0 \mathrm{mM})$ for the indicated time periods.

in cells treated with 4-MU compared to control cells at all time points examined. The percentages of cells treated with $1 \mathrm{mM} 4-\mathrm{MU}$ in the sub-G0/G1 phase were $4.04,9.44$, and $12.27 \%$ after 24,48 and $72 \mathrm{~h}$ of incubation, respectively (Fig. 5D). In particular, samples with cells treated with $1 \mathrm{mM}$ 4MU showed percentages of apoptotic cells that were approximately 24 times higher than control samples (Fig. 5D). Next, to clarify the effect of 4-MU on apoptosis-related proteins, we measured $B A X$ mRNA and protein expression levels using real-time RT-PCR and western blotting. The 4-MU-treated cells demonstrated higher levels of expression of $B A X$ mRNA than control cells at all-time points examined (Fig. 6A). In addition, we observed that 4-MU $(0.6 \mathrm{mM}$ and $1.0 \mathrm{mM})$ caused dose-dependent increases in BAX protein levels at 48 and $72 \mathrm{~h}$ (Fig. 6C and D). These results indicated that 4-MU decreased cell survival mainly through an extrinsic apoptosis pathway. It is conceivable that the 4-MU-treated cells showed no change in the levels of BAX protein at $24 \mathrm{~h}$ (Fig. 6B) as a reflection of a lapse in time from mRNA expression to protein synthesis.

\section{Discussion}

In recent studies, 4-MU has shown anticancer effects involving apoptotic, anti-invasive and anti-angiogenic pathways in vitro and in vivo $(28,29,36,37)$. We hypothesized that treatment of canine CF33 mammary tumor cells with 4-MU might decrease the HA matrix, leading to the inhibition of tumor cell growth and the induction of apoptosis. Our experiments revealed that 4-MU-associated inhibition of HA synthesis was accompanied by a reduction of HAS2 mRNA levels, as well as marked growth retardation and apoptosis associated with increases in $B A X$ mRNA and protein expression. Our findings suggest that 4-MU has potent anticancer effects in breast cancer cells in dogs.

Previous studies have reported that HA plays a critical role in the proliferation, progression, angiogenesis, invasion and metastasis of several types of cancer. HA is a ubiqui- tous extracellular matrix (ECM) component of the tumor environment, particularly in the stroma, where its accumulation is observed in various types of cancer, and it has been known to be linked to tumor progression and poor survival of patients with cancer $(9,13-15)$. Increased concentrations of HA indicate that its metabolism is altered in cancer cells, and the imbalance of HA synthesis and/or degradation may play an important role in tumor progression (33). HAS2 mainly produces high molecular weight HA (200-2000 kDa) and it is involved in a variety of both pathological and physiological activities, including proliferation, differentiation, inflammation, epithelial to mesenchymal transition (EMT) and cancer progression (38-40). Furthermore, it was recently reported that HAS2 plays an important prometastatic role by generating a favorable microenvironment of cancer stem-like cells (41). In human breast cancer cells, HAS2 is increasingly recognized as a key molecule for maintenance of the malignant phenotype $(17,35)$. In this study, we showed that 4-MU treatment in CF33 cells resulted in inhibition of cell growth associated with downregulation of $H A S 2$ mRNA expression. Our data are consistent with a recent report showing that HAS2 is related to inhibition of cell proliferation, migration and metastasis in human breast cancer cells (35). Therefore, 4-MU may also serve as a potential therapeutic agent for breast cancer in dogs. Moreover, our findings suggest that the canine mammary tumor may be a suitable model for the study of the function of HA in human breast cancer cells.

Newly synthesized HA molecules are extruded onto the cell surface for assembly into pericellular or extracellular matrices, and they can also be retained on the cell surface by binding to HA receptors (CD44, RHAMM, Toll-like receptor-4) $(9,42)$. In particular, it is well known that an HA-CD44 interaction can lead to the activation of intracellular signaling pathways that affect the proliferation, survival, migration and invasion of cancer cells $(43,44)$. Recent studies have shown that the HA-CD44 interaction activates the PI3K-Akt and Ras-MAPK pathways, leading to cell motility and cell survival-signaling 
pathways (45). In prostate cancer cells, 4-MU induced a dosedependent decrease in phosphorylated Akt levels, indicating that Akt signaling is a critical mechanism in the antitumor activity (28). Our results suggested that 4-MU may indirectly inhibit activation of the PI3K-Akt and Ras-MAPK pathways via suppression of HA synthesis and perturbation of the HA-CD44 interaction.

There are at least 2 different steps in the inhibitory effect of 4-MU on HA synthesis. First, 4-MU results in depletion of UDP-GlcUA (26). Second, expression levels of HAS mRNAs are downregulated by 4-MU, resulting in the inhibition of HA synthesis (27). Kultti et al reported that levels of HAS2 and/or HAS3 mRNA were downregulated in all cancer cell lines examined (27), which is not consistent with our findings, in which levels of HAS3 mRNA increased after treatment with 4-MU. A possible explanation for the results of our study is that 4-MU causes positive feedback for HAS3 mRNA expression to compensate for the inhibition of HA synthesis. These observations are likely to occur in HA-associated genes $(17,35)$. Our results further showed that the downregulation of HAS2 after treatment with 4-MU induced marked growth retardation and apoptosis in CF33 cells. This observation supports the notion that HAS2 preferentially promotes cancer progression compared with HAS3 in CF33 cells, since the levels of $H A S 2$, but not $H A S 3$, expression were correlated with the rate of induction of growth inhibition and apoptosis.

Our present study is the first to show that 4-MU might be a potential agent for improved chemotherapy against breast cancer in dogs. The actions of 4-MU in the CF33 cells were similar to those shown in humans, suggesting that dogs may be suitable as an animal models for analyzing the role of HA in human breast cancer.

\section{Acknowledgements}

The authors thank T. Oyama, M. Higashi and K. Azuma for their critical discussions. This study was supported in part by a grant-in-aid from the Life Science Research Center Nihon University (To T.S.), a grant-in-aid from Nihon University (To T.S.) and funds from the Laboratory of Veterinary Pharmacology, Nihon University College of Bioresource Sciences.

\section{References}

1. Priester WA and Mantel N: Occurrence of tumors in domestic animals. Data from 12 United States and Canadian colleges of veterinary medicine. J Natl Cancer Inst 47: 1333-1344, 1971.

2. Sorenmo K: Canine mammary gland tumors. Vet Clin North Am Small Anim Pract 33: 573-596, 2003.

3. Graham JC and Myers RK: The prognostic significance of angiogenesis in canine mammary tumors. J Vet Intern Med 13: 416-418, 1999.

4. Nieto A, Pena L, Perez-Alenza MD, Sanchez MA, Flores JM and Castano M: Immunohistologic detection of estrogen receptor alpha in canine mammary tumors: clinical and pathologic associations and prognostic significance. Vet Pathol 37: 239-247, 2000.

5. Uva P, Aurisicchio L, Watters J, Loboda A, Kulkarni A, Castle J, Palombo F, Viti V, Mesiti G, Zappulli V, Marconato L, Abramo F, Ciliberto G, Lahm A, La Monica N and de Rinaldis E: Comparative expression pathways analysis of human and canine mammary tumors. BMC Genomics 10: 135, 2009.

6. Standberg JD and Goodman DG: Animal model of human disease: canine mammary neoplasia. Am J Pathol 75: 225-228, 1974.
7. Pinho SS, Carvalho S, Cabral J, Reis CA and Gartner F: Canine tumors: a spontaneous animal model of human carcinogenesis. Transl Res 159: 165-172, 2012.

8. Weismann B, Rapport MM, Linker A and Meyer K: Isolation of the aldobionic acid of umbilical cord hyaluronic acid. J Biol Chem 205: 205-211, 1953

9. Toole BP: Hyaluronan: from extracellular glue to pericellular cue. Nat Rev Cancer 4: 528-539, 2004.

10. Turley EA, Noble PW and Bourguignon LY: Signaling properties of hyaluronan receptors. J Biol Chem 277: 4589-4592, 2002.

11. Fraser JR, Laurent TC and Laurent UB: Hyaluronan: its nature, distribution, functions and turnover. J Intern Med 242: 27-33, 1997.

12. Menzel E and Farr C: Hyaluronidase and its substrate hyaluronan: biochemistry, biological activities and therapeutic uses. Cancer Lett 131: 3-11, 1998.

13. Auvinen P, Tammi RH, Parkinen J, Tammi M, Agren U, Johansson R, Hirvikoski P, Eskelinen M and Kosma VM: Hyaluronan in peritumoral stroma and malignant cells associates with breast cancer spreading and predicts survival. Am J Pathol 156: 529-536, 2000.

14. Anttila MA, Tammi RH, Tammi MI, Syrjanen KJ, Saarikoski SV and Kosma VM: High levels of stromal hyaluronan predict poor disease outcome in epithelial ovarian cancer. Cancer Res 60: $150-155,2000$

15. Lipponen P, Aaltomaa S, Tammi R, Tammi M, Agren U and Kosma VM: High stromal hyaluronan level is associated with poor differentiation and metastasis in prostate cancer. Eur J Cancer 37: 849-856, 2001.

16. Golshani R, Lopez L, Estrella V, Kramer M, Iida N and Lokeshwar VB: Hyaluronic acid synthase-1 expression regulates bladder cancer growth, invasion, and angiogenesis through CD44. Cancer Res 68: 483-491, 2008.

17. Udabage L, Brownlee GR, Waltham M, Blick T, Walker EC, Heldin P, Nilsson SK, Thompson EW and Brown TJ: Antisensemediated suppression of hyaluronan synthase- 2 inhibits the tumorigenesis and progression of breast cancer. Cancer Res 65: 6139-6150, 2005.

18. Liu N, Gao F, Han Z, Xu X, Underhill CB and Zhang L: Hyaluronan synthase 3 overexpression promotes the growth of TSU prostate cancer cells. Cancer Res 61: 5207-5214, 2001.

19. Cichy J and Pure E: The liberation of CD44. J Cell Biol 161: 839-843, 2003.

20. Cheung WF, Cruz TF and Turley EA: Receptor for hyaluronanmediated motility (RHAMM), a hyaladherin that regulates cell responses to growth factors. Biochem Soc Trans 27: 135-142, 1999.

21. Itano N, Zhuo L and Kimata K: Impact of the hyaluronan-rich tumor microenvironment on cancer initiation and progression. Cancer Sci 99: 1720-1725, 2008.

22. Gotte M and Yip GW: Heparanase, Hyaluronan, and CD44 in cancers: a breast carcinoma perspective. Cancer Res 66: 10233-10237, 2006.

23. Serra M, Rabanal RM, Miquel L, Domenzain C and Bassols A: Differential expression of CD44 in canine melanocytic tumours. J Comp Path 130: 171-180, 2004.

24. Paltian V, Alldinger S, Baumgartner W and Wohlsein P: Expression of CD44 in canine mammary tumours. J Comp Path 141: 237-247, 2009.

25. Nakamura T, Funahashi M, Takagaki K, Munakata H, Tanaka K, Saito Y and Endo M: Effect of 4-methylumbelliferone on cell-free synthesis of hyaluronic acid. Biochem Mol Biol Int 43: 263-268, 1997.

26. Kakizaki I, Kojima K, Takagaki K, Endo M, Kannagi R, Ito M, Maruo Y, Sato H, Yasuda T, Mita S, Kimata K and Itano N: A novel mechanism for the inhibition of hyaluronan biosynthesis by 4-Methylumbelliferone. J Biol Chem 279: 33281-33289, 2004.

27. Kultti A, Pasonen-Seppanen S, Jauhiainen M, Rilla KJ, Karna R, Pyoria E, Tammi RH and Tammi MI: 4-Methylumbelliferone inhibits hyaluronan synthesis by depletion of cellular UDP-glucuronic acid and downregulation of hyaluronan synthase 2 and 3. Exp Cell Res 315: 1914-1923, 2009.

28. Lokeshwar VB, Lopez LE, Munoz D, Chi A, Shirodkar SP Lokeshwar SD, Escudero DO, Dhir N and Altman N: Antitumor activity of hyaluronic acid synthesis inhibitor 4-methylumbelliferone in prostate cancer cells. Cancer Res 70: 2613-2623, 2010.

29. Yoshihara S, Kon A, Kudo D, Nakazawa H, Kakizaki I, Sasaki M, Endo $\mathrm{M}$ and Takagaki K: A hyaluronan synthase suppressor, 4-methylumbelliferone, inhibits liver metastasis of melanoma cells. FEBS Lett 579: 2722-2726, 2005. 
30. Knudson W and Knudson CB: Assembly of a chondrocyte-like pericellular matrix on non-chondrogenic cells. Role of the cell surface hyaluronan receptors in the assembly of a pericellular matrix. J Cell Sci 99: 227-235, 1991.

31. Hansen MB, Nielsen SE and Berg K: Re-examination and further development of a precise and rapid dye method for measuring cell growth/cell kill. J Immunol Methods 119: 203-210, 1989.

32. Twentyman PR and Luscombe M: A study of some variables in a tetrazolium dye (MTT) based assay for cell growth and chemosensitivity. Br J Cancer 56: 279-285, 1987.

33. Saito T, Kawana H, Azuma K, Toyoda A, Fujita H, Kitagawa $\mathrm{M}$ and Harigaya K: Fragmented hyaluronan is an autocrine chemokinetic motility factor supported by the HAS2-HYAL2/ CD44 system on the plasma membrane. Int J Oncol 39: 13111320,2011

34. Simpson M, Reiland J, Burger S, Furcht L, Spicer A, Oegema T and MaCarthy JB: Hyaluronan synthase elevation in metastatic prostate carcinoma cells correlates with hyaluronan surface retention, a prerequisite for rapid adhesion to bone marrow endothelial cells. J Biol Chem 276: 17949-17957, 2001.

35. Li Y, Li L, Brown TJ and Heldin P: Silencing of hyaluronan synthase 2 suppresses the malignant phenotype of invasive breast cancer cells. Int J Cancer 120: 2557-2567, 2007.

36. Xia W, Spector S, Hardy L, Zhao S, Saluk A, Alemane L and Spector NL: Tumor selective G2/M cell cycle arrest and apoptosis of epithelial and hematological malignancies by BBL22, a benzazepine. Proc Natl Acad Sci USA 97: 7494-7499, 2000.

36. Arai E, Nishida Y, Wasa J, Urakawa H, Zhuo L, Kimata K, Kozawa E, Futamura N and Ishiguro N: Inhibition of hyaluronan retention by 4-methylumbelliferone suppresses osteosarcoma cells in vitro and lung metastasis in vivo. Br J Cancer 105: 1839-1849, 2011.

37. Urakawa H, Nishida Y, Wasa J, Arai E, Zhuo L, Kimata K, Kozawa E, Futamura $\mathrm{N}$ and Ishiguro N: Inhibition of hyaluronan synthesis in breast cancer cells by 4 -methylumbelliferone suppresses tumorigenicity in vitro and metastatic lesions of bone in vivo. Int J Cancer 130: 454-466, 2012.
38. Camenisch TD, Spicer AP, Brehm-Gibson T, Biesterfeldt J, Agustine ML, Calabro A Jr, Kubalak S, Klewer SE and McDonald JA: Disruption of hyaluronan synthase-2 abrogates normal cardiac morphogenesis and hyaluronan-mediated transformation of epithelium to mesenchyme. J Clin Invest 106: 349-360, 2000.

39. Vigetti D, Genasetti A, Karousou E, Viola M, Moretto P, Clerici M, Deleonibus S, De Luca G, Hascall VC and Passi A: Proinflammatory cytokines induce hyaluronan synthesis and monocyte adhesion in human endothelial cells through hyaluronan synthase 2 (HAS2) and the nuclear factor-kappaB (NF-kappaB) pathway. J Biol Chem 285: 24639-24645, 2010.

40. Itano $\mathrm{N}$ and Kimata K: Mammalian hyaluronan synthases. IUBMB Life 54: 195-199, 2002.

41. Okuda H, Kobayashi A, Xia B, Watabe M, Pai SK, Hirota S, Xing F, Liu W, Pandey PR, Fukuda K, Modur V, Ghosh A, Wilber A and Watabe K: Hyaluronan synthase HAS2 promotes tumor progression in bone by stimulating the interaction of breast cancer stem-like cells with macrophages and stromal cells. Cancer Res 72: 537-547, 2012.

42. Sironen RK, Tammi M, Tammi R, Auvinen PK, Anttila M and Kosma VM: Hyaluronan in human malignancies. Exp Cell Res 317: 383-391, 2011.

43. Bourguignon LY, Zhu H, Chu A, Iida N, Zhang L and Hung MC: Interaction between the adhesion receptor, CD44, and the oncogene product, p185HER2, promotes human ovarian tumor cell activation. J Biol Chem 272: 27913-27918, 1997.

44. Ouhit A, Abd Elmageed ZY, Abdraboh ME, Lioe TF and Raj MH: In vivo evidence for the role of CD44s in promoting breast cancer metastasis to the liver. Am J Pathol 171: 2033-2039, 2007.

45. Sohara Y, Ishiguro N, Machida K, Kurata H, Thant AA, Senga T, Matsuda S, Kimata K, Iwata $\mathrm{H}$ and Hamaguchi M: Hyaluronan activates cell motility of $\mathrm{v}$-Src-transformed cells via Ras-mitogenactivated protein kinase and phosphoinositide 3-kinase-Akt in a tumor-specific manner. Mol Biol Cell 12: 1859-1868, 2001. 